\title{
Production Planning Based on Multi-Level Process Flow
}

\author{
Zhou Qiu-Zhong ${ }^{1}, \mathrm{Ji} \mathrm{Fa}^{1}$ and Tao $\mathrm{Ze}^{2,{ }^{*}}$ \\ ${ }^{I}$ School of Automobile \& Traffic, Shenyang Ligong University, Shenyang, China \\ ${ }^{2}$ School of Mechanical Engineering, Shenyang Ligong University, Shenyang, China
}

\begin{abstract}
To improve correctness and reasonability of the enterprise production plan and subsequent promote planning and control capability of enterprises, this paper proposes a production planning method based on multi-level process flow. First, this paper proposes the space-based multi-level process flow idea and establishes mathematic model and formalized expression of multi-level process flow according to the actual division of the enterprise's production space and manufacturing process of products in space units at different levels. Meanwhile, this paper proposes the concepts of the JOB lead time, POS lead time, ACC lead time and shop lead time, and gives the detailed computing method of different lead times. Based on above work, this paper analyzes mapping of process flow and production plans, and expounds specific computing method of flow unit delivery time at different levels. Finally, this paper proves correctness and feasibility of this idea and method via the actual cases.
\end{abstract}

Keywords: Delivery time, Lead time, Multi-level process flow, Production planning, Production space.

\section{INTRODUCTION}

Reasonable making of the production plan is the key for manufacturers to smoothly carry out production management. Today the production planning and control is based on MBOM and subordinate bill of process (BOP) of different stations under the BOM-based product data organization mode [1-7]. It is two-level plan making mode. First, make the production plan of different part objects according to the MBOM of products and their lead time and then make the process production plan according to the BOP of different parts. Although MBOM regulates composition and quantity relation of part objects in actual assembly and the parallel crossing jobs are considered in actual production, correct assembly time sequence part objects in a group and component structure is not specifically regulated, so the production lead time of parts should be summarized according to the time required in assembly BOP. The computing process is complicated and time-consuming. MBOM does not regulate the specific and detailed flowing process of different part objects inside the enterprises, so the made production plan is lack of integrity, especially the complicated products based on assembly.

Based on research achievements at home and abroad, this paper proposes the space-based multi-level process flow model according to the space unit division and material flowing relation. Based on this model, this paper proposes the idea and method for computing precise lead time of the materials and making the multi-level production

\footnotetext{
*Address correspondence to this author at the Nan-ping Middle Road, Shenyang, China. Postcard: 110159 ; Tel: 13889114386;

E-mail: zqz7@sohu.com
}

plan. This method will improve correctness and reasonability of production planning of enterprises and further promote planning and control capability of enterprises.

\section{MULTI-LEVEL PROCESS FLOW}

In present product manufacturing model, component manufacturing and product assembly work of different product objects are carried on in various workshops, such as general assembly shop, subassembly shop, component workshop, warehouse and so on. So workshop layer manufacturing process comes into being according to the flow relation between different workshops. Inside the workshop, the production work of accessory objects is fulfilled through different ACC and POS in a certain order, so as to form the ACC and POS process flow. JOB is the most basic organization unit of the process and composed of steps which are the specific operational order to guide the skilled workers to finish the actual manufacturing work. According to the front and back ordinal relation of each working procedure, the JOB flow takes shape. So the multi-level process flow which is composed of workshop, ACC, POS, JOB comes into being as shown in Fig. (1).

If $P F_{m}\left(\operatorname{Prod}-O u t_{m}^{i}\right)$ is used to represent the process flow of number $m$ layer of the production object Prod-Out ${ }_{m}^{i}$, while $P F U_{m}^{i, j}$ represents the number $i$ process flow unit of the layer $m$ which take the afterwards process flow unit number $j$, so the process flow of workshop, ACC, POS and JOB layer can be expressed as the following: 


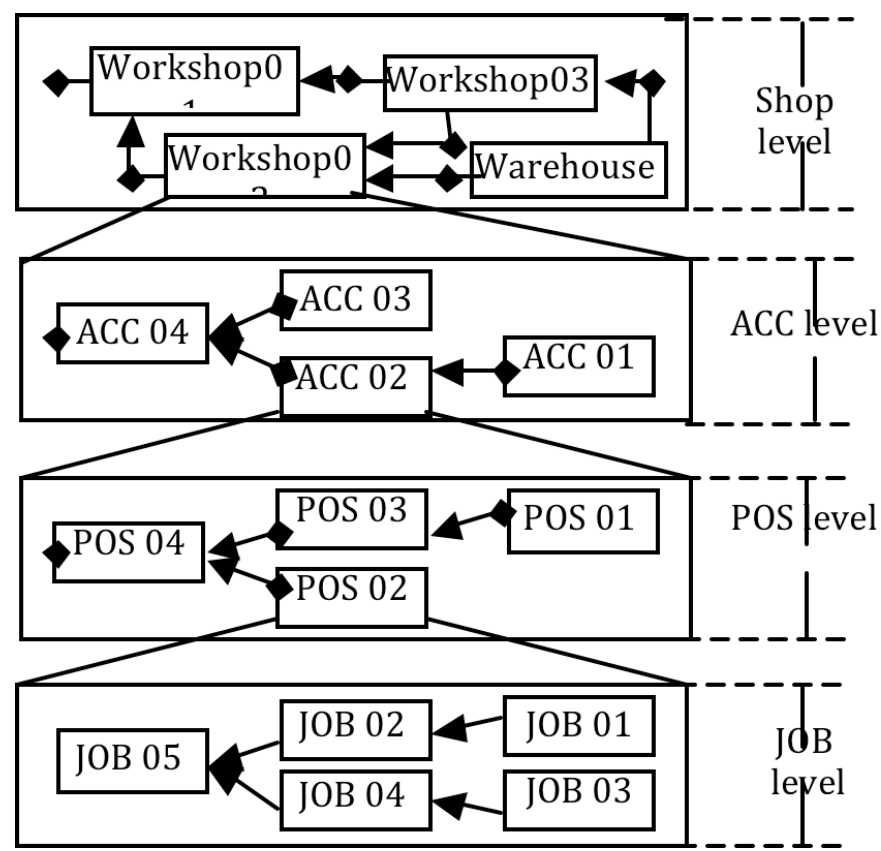

Fig. (1). Multi-level process flow.

$P F_{m}\left(\operatorname{Pr} o d-O u t_{m}\right)=\left\{P F U_{m}^{1,2}, P F U_{m}^{2,3}, \ldots, P F U_{m}^{i, j} \ldots, P F U_{m}^{I, *}\right\}$

Among which:

$m=\left\{\begin{array}{l}\text { 1, workshiplevel; } \\ \text { 2, ACClevel; } \\ 3, \text { POSlevel; } \\ \text { 4, JOBlevel; }\end{array}\right.$

Any process flow unit $P F U_{m}^{i, j}$ works in the way in which the input object $\operatorname{Pr} o d-\operatorname{In}_{m}^{i}$ is transformed into output object Prod-Out ${ }_{m}^{i}$ through certain production space $S P U_{m}^{k}$, which means:

$P F U_{m}^{i, j}=\left(S P U_{m}^{k}, \operatorname{Prod}-I_{m}^{i}, \operatorname{Pr} o d-O u t_{m}^{i}\right)$

Among which:

$\operatorname{Pr} o d-I n_{m}^{i}=\left\{\operatorname{Pr} o d-I n_{m}^{i, 1}, \operatorname{Pr} o d-I n_{m}^{i, 2}, \ldots, \operatorname{Pr} o d-I n_{m}^{i, n}\right\}$

According to the ordinal relations of each process flow unit, the output of the previous unit becomes the input of the next unit, thus the following relation can be found:

$\operatorname{Pr} o d-O u t_{m}^{i} \in \operatorname{Pr} o d-\operatorname{In}_{m}^{j}$

At the same time, the inclusion relation exists between upper and lower layer process unit, it can be expressed in the following way:

$$
P F U_{m}^{i, j}=P F_{m+1}\left(\operatorname{Prod}-O u t_{m}^{i}\right), m \in\{1,2,3\}
$$

In addition, the output product object of any layer process must be the output object of its last process flow unit, which is shown as follows:

$$
\operatorname{Pr} o d-O u t_{m}=\operatorname{Pr} o d-O u t_{m}^{I}
$$

\section{COMPUTING OF PRECISE LEAD TIME}

The lead time plays an important role as the important parameter in production planning, so it is necessary to precisely compute the lead time. Like the levels in the multilevel process flow, the lead time is divided into the JOB lead time, POS lead time, ACC lead time and shop lead time. The concepts and their computing methods are described as follows.

\subsection{Job Lead Time}

The JOB lead time indicates the lead time of a completed JOB flow unit $\mathrm{PFU}_{4}^{i, j}$ to the completed subsequent JOB flow unit $\mathrm{PFU}_{4}^{j,{ }^{*}}$ in the JOB flow $\mathrm{PF}_{4}\left(\mathrm{Pr} o d-O u t_{4}\right)$ of the production part object $\operatorname{Prod}-\mathrm{Out}_{4}$ and is expressed as $T H\left(\mathrm{PFU}_{4}^{i, j}\right)$.

Shown as the Fig. (2), the JOB lead time $T H\left(P F U_{4}^{i, j}\right)$ of this JOB should be more than or equal to the production cycle $T\left(\mathrm{PFU}_{4}^{j,{ }^{*}}\right)$ of subsequent JOB.

\subsection{POS Lead Time}

The POS lead time indicates the lead time of a completed POS flow unit $\mathrm{PFU}_{3}^{i, j}$ to the completed subsequent 


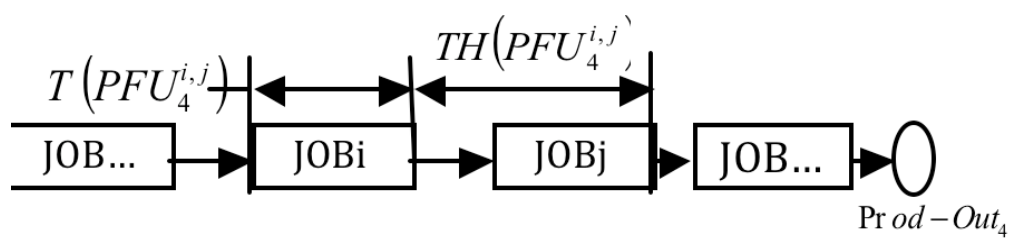

Fig. (2). JOB flow.

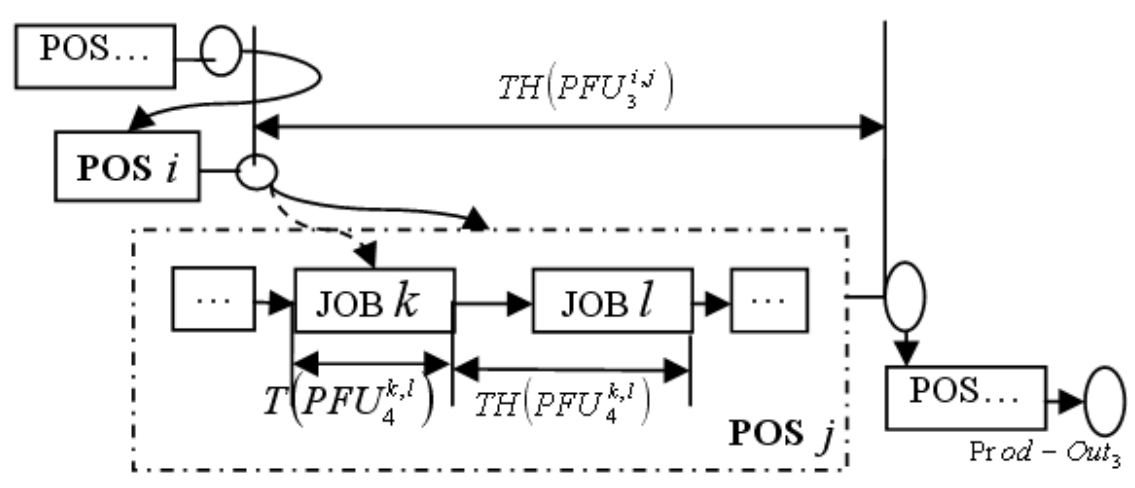

Fig. (3). POS flow.

POS flow unit $\mathrm{PFU}_{3}{ }^{j,{ }^{*}}$ in the POS flow $\mathrm{PF}_{3}\left(\operatorname{Prod}-\mathrm{Out}_{3}\right)$ of the production part object Prod-Out ${ }_{3}$ and is expressed as $T H\left(\mathrm{PFU}_{3}^{i, j}\right)$.

The output object of any POS flow unit becomes the input object of subsequent POS flow unit in the POS flow, but this input object may occur at any JOB flow unit in the subsequent POS flow units and may not occur at the first JOB flow unit in the subsequent POS flow units, shown as the Fig. (3). Assume that the production output object of the POS flow unit $P F U_{3}^{i, j}$ is truly used at $\mathrm{k}^{\text {th }}$ JOB flow unit in the subsequent POS process unit $P F U_{3}^{j,{ }^{*}}$, the lead time $T H\left(\mathrm{PFU}_{3}^{i, j}\right)$ of this POS flow unit is equal to the production cycle $T\left(P F U_{4}^{k, l}\right)$ of $\mathrm{k}^{\text {th }} \mathrm{JOB}$ flow unit in subsequent POS flow unit $\mathrm{PFU}_{3}^{j,{ }^{*}}$ plus the sum of the JOB lead time of $\mathrm{k}^{\text {th }} \mathrm{JOB}$ flow unit and all subsequent JOB flow units, namely:

$T H\left(\mathrm{PFU}_{3}^{i, j}\right)=T\left(\mathrm{PFU}_{4}^{k, l}\right)+\sum_{z=k}^{K} T H\left(\mathrm{PFU}_{4}^{z,{ }^{*}}\right)$

\subsection{ACC Lead Time}

The ACC lead time indicates the lead time of a completed ACC flow unit $P F U_{2}^{i, j}$ to the completed subsequent ACC flow unit $P F U_{2}^{j, *}$ in the ACC flow $\mathrm{PF}_{2}\left(\mathrm{Prod}-\mathrm{Out}_{2}\right)$ of the production part object Prod $-\mathrm{Out}_{2}$ and is expressed as $T H\left(P F U_{2}^{i, j}\right)$.
The output object of any ACC flow unit becomes the input object of subsequent ACC flow unit in the ACC flow, but this input object may occur at any POS flow unit in the subsequent ACC flow units and may not occur at the first POS flow unit in the subsequent ACC flow units, shown as the Fig. (4). Assume that the production output object of the ACC flow unit $P F U_{2}^{i, j}$ is truly used at $\mathrm{m}^{\text {th }} \mathrm{JOB}$ flow unit of $\mathrm{k}^{\text {th }}$ POS flow unit in the subsequent ACC process unit $P F U_{2}^{j, *}$, the lead time $T H\left(P F U_{2}^{i, j}\right)$ of this ACC flow unit is equal to the production cycle $T\left(P F U_{4}^{m, n}\right)$ of $\mathrm{m}^{\text {th }}$ JOB flow unit of $\mathrm{k}^{\text {th }}$ POS flow unit in subsequent ACC flow unit $P F U_{2}^{j \text {,* }}$ plus the sum of the JOB lead time of $\mathrm{m}^{\text {th }}$ JOB flow unit of $\mathrm{k}^{\text {th }}$ POS flow unit and all subsequent JOB flow units and the sum of POS lead time of $\mathrm{k}^{\text {th }}$ POS and all subsequent POS flow units, namely:

$$
\begin{aligned}
& T H\left(P F U_{2}^{i, j}\right)=T\left(P F U_{4}^{m, n}\right)+\sum_{y=m}^{M} T H\left(P F U_{4}^{y,{ }^{*}}\right) \\
& +\sum_{z=k}^{K} T H\left(P F U_{3}^{z,{ }^{*}}\right)
\end{aligned}
$$

\subsection{Shop Lead Time}

The shop lead time indicates the lead time of a completed position shop unit $P F U_{1}^{i, j}$ to the completed subsequent shop flow unit $P F U_{1}^{j, *}$ in the shop flow $P F_{1}\left(\operatorname{Prod}-O u t_{1}\right)$ of the production part object Prod-Out and is expressed as $T H\left(P F U_{1}^{i, j}\right)$. 


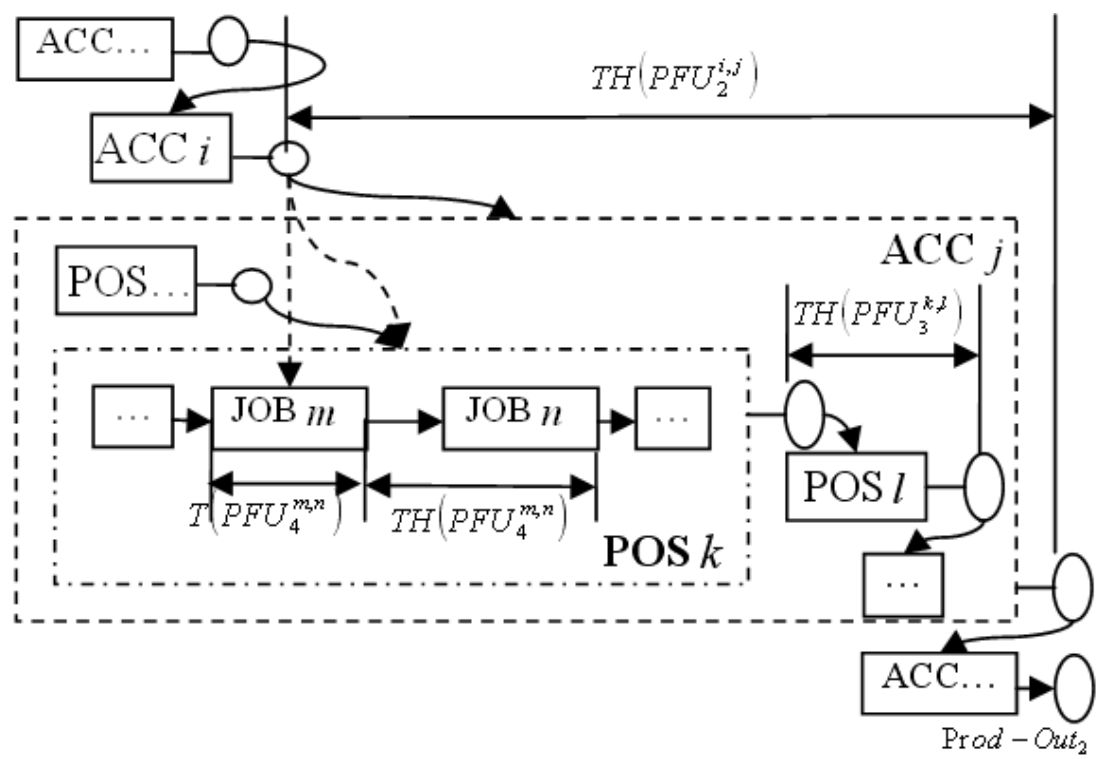

Fig. (4). ACC flow.

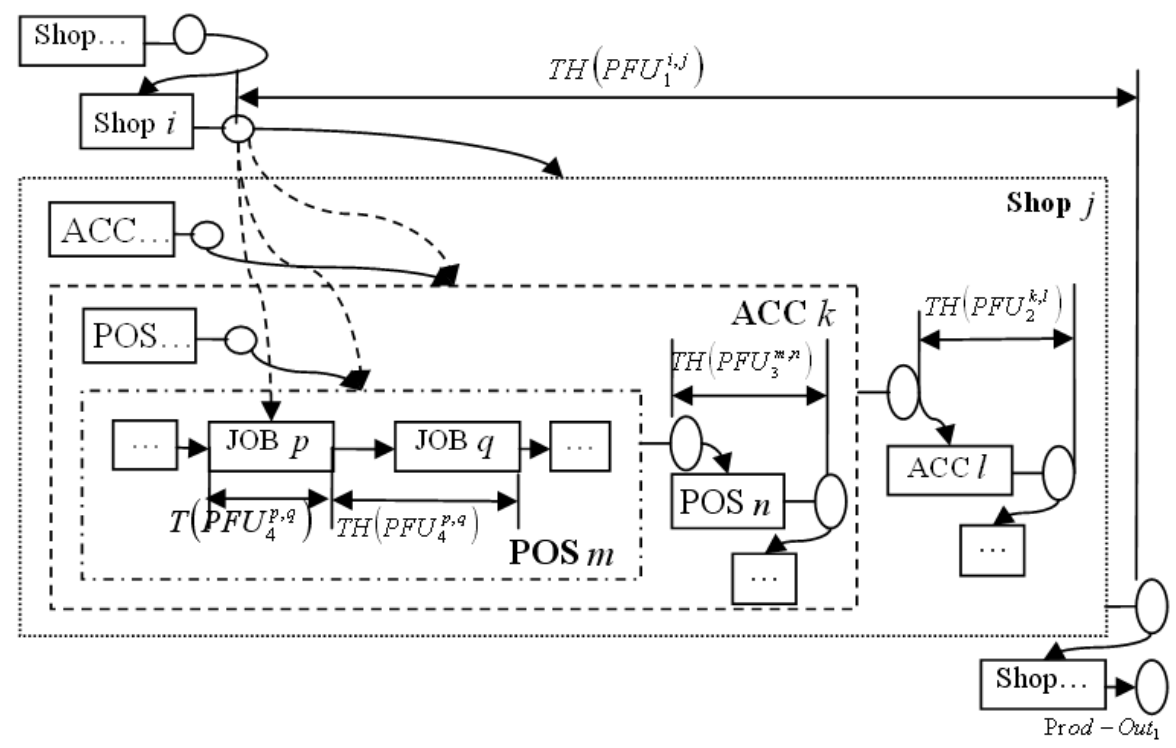

Fig. (5). Shop flow.

The output object of any shop flow unit becomes the input object of subsequent shop flow unit in the shop flow, but this input object may occur at any ACC flow unit in the subsequent shop flow units and may not occur at the first ACC flow unit in the subsequent shop flow units, shown as the Fig. (5). Assume that the production output object of the shop flow unit $P F U_{1}^{i, j}$ is truly used at $\mathrm{p}^{\text {th }}$ JOB flow unit of $\mathrm{m}^{\text {th }}$ POS flow unit of $\mathrm{k}^{\text {th }} \mathrm{ACC}$ flow unit in the subsequent shop process unit $P F U_{2}^{j,{ }^{*}}$, the lead time $T H\left(P F U_{1}^{i, j}\right)$ of this shop flow unit is equal to the production cycle $T\left(P F U_{4}^{p, q}\right)$ of $\mathrm{p}^{\text {th }} \mathrm{JOB}$ flow unit of $\mathrm{m}^{\text {th }}$ POS flow unit of $\mathrm{k}^{\text {th }}$ ACC flow unit in subsequent shop flow unit $P F U_{1}^{j,{ }^{*}}$ plus the sum of the JOB lead time of $\mathrm{p}^{\text {th }} \mathrm{JOB}$ flow unit of $\mathrm{m}^{\text {th }}$ POS flow unit of $\mathrm{k}^{\text {th }}$ ACC flow unit and all subsequent JOB flow units, the sum of POS lead time of $\mathrm{m}^{\text {th }}$ POS flow unit of $\mathrm{k}^{\text {th }} \mathrm{ACC}$ flow unit and all subsequent POS flow units, and the sum of the ACC lead time of $\mathrm{k}^{\text {th }}$ $\mathrm{ACC}$ and all subsequent ACC flow units, namely:

$$
\begin{aligned}
& T H\left(P_{1} U_{1}^{i, j}\right)=T\left(P_{4}^{p, q}\right)+\sum_{x=p}^{P} T H\left(P_{4} U_{4}^{x, *}\right) \\
& +\sum_{y=m}^{M} T H\left(P F U_{3}^{y,{ }^{*}}\right)+\sum_{z=k}^{K} T H\left(P F U_{2}^{z, *}\right)
\end{aligned}
$$




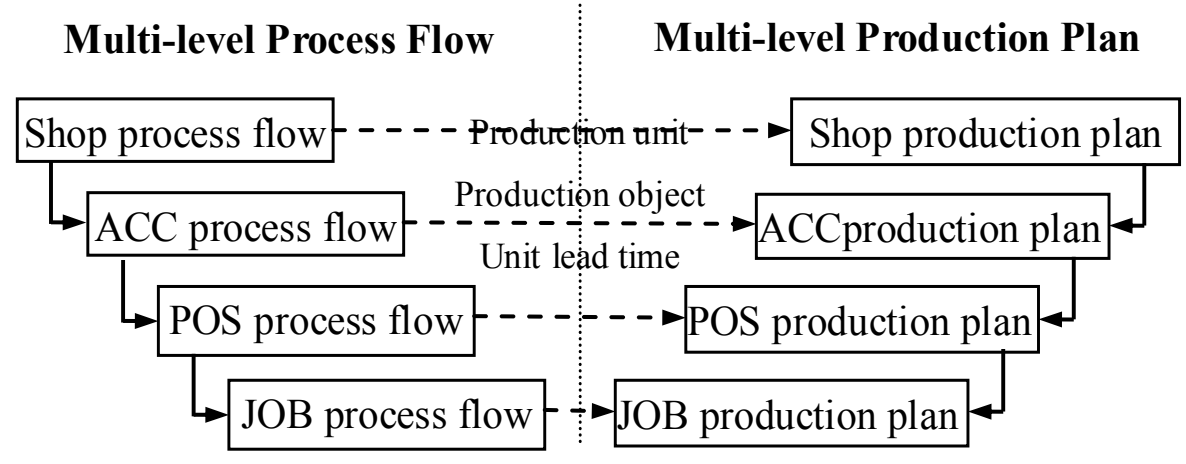

Fig. (6). Mapping of multi-level process flow and plans at different levels.

\section{PRODUCTION PLANNING IN MULTI-LEVEL PROCESS FLOW MODE}

\subsection{Basic Idea}

The basic idea is to respectively compute the planned delivery time of the space flow units at different levels from up shop level to down ACC level, POS level and JOB level and form the shop production plan, ACC level production plan, POS level production plan and JOB level production plan in turn during the production planning under space-based multi-level process data organization mode, provided that the delivery time of the products and the space flow unit at different levels are known. This multi-level production plan and multi-level process flow are mapped one by one, shown as the Fig. (6). The precise delivery time of the flow units at the corresponding level can be quickly and accurately prepared based on the flow unit, production object and previous lead time at different levels to form the complete production plan and ensure timely completion of the production task.

\subsection{Compute Delivery Time of Flow Unit}

When the production output product object is Prod-Out and the completion delivery time is $T_{\text {delivery }}(\operatorname{Pr}$ od-Out $)$ in the multi-level space process flow mode, the delivery time of different flow units is computed as follows.

First, find its shop process flow $P F_{1}(\operatorname{Prod}-O u t)$ and the final shop flow unit $P F U_{1}^{I, *}$ of output this product object according to the product object $\mathrm{Pr}$ od-Out, the delivery time $T_{\text {delivery }}\left(P F_{1}(\operatorname{Prod}-O u t)\right)$ of the shop process flow of this product object is equal to the delivery time $T_{\text {delivery }}\left(P F U_{1}^{I, *}\right)$ of the final shop flow unit and the delivery time $T_{\text {delivery }}(\operatorname{Prod}-\mathrm{Out})$ of this product object, namely:

$$
T_{\text {delivery }}\left(P F_{1}(\operatorname{Prod}-O u t)\right)=T_{\text {delivery }}\left(P F U_{1}^{I, *}\right)
$$

$=T_{\text {delivery }}(\operatorname{Pr}$ od-Out $)$

Then identify the completion delivery time $T_{\text {delivery }}\left(P F U_{1}^{i, j}\right)$ of each shop flow unit $P F U_{1}^{i, j}$ in inverse order in turn, which is the completion delivery time $T_{\text {delivery }}\left(\operatorname{PFU}_{1}^{j,{ }^{*}}\right)$ of the subsequent shop flow units minus the shop lead time $T H\left(P F U_{1}^{i, j}\right)$ of this shop flow unit, namely:

$$
T_{\text {delivery }}\left(P F U_{1}^{i, j}\right)=T_{\text {delivery }}\left(P F U_{1}^{j, *}\right)-T H\left(P F U_{1}^{i, j}\right)
$$

For each shop flow unit and its output object, find its ACC process flow, identify the completion delivery time of each ACC flow unit in inverse order in turn, which is the completion delivery time of the subsequent ACC minus the ACC lead time of this ACC flow units. Similarly, the POS delivery time and JOB delivery time can be further identified.

So the completion delivery time of the flow unit at different levels is computed as follows:

$$
T_{\text {delivery }}\left(P F U_{m}^{i, j}\right)=T_{\text {delivery }}\left(P F U_{m}^{j,{ }^{*}}\right)-T H\left(P F U_{m}^{i, j}\right)
$$

Wherein

$$
\begin{aligned}
& T_{\text {delivery }}\left(P F U_{m}^{I, *}\right)=T_{\text {delivery }}\left(P F_{m}\left(\operatorname{Pr} \text { od-Out }{ }_{m}\right)\right) \\
& T_{\text {delivery }}\left(P F_{1}\left(\operatorname{Pr} \text { od-Out } t_{1}\right)\right)=T_{\text {delivery }}(\operatorname{Prod}-\text { Out }) .
\end{aligned}
$$

\section{COMPUTING CASE}

Assume that a product object Prod-Out is formed by assembling the output part objects of the shop 2, 3 and 4 via the ACC flow of ACC 10, 20, 30 and 40 at the shop 1. The ACC 20 is composed of the POS 10, 20, 30 and 40 and the POS 20 is composed of JOB 10, 20, 30 and 40. The detailed production process flow and material relation are shown as the Fig. (7). Here assume that the production cycle of the JOB flow units is 2 hours and ignore the material 


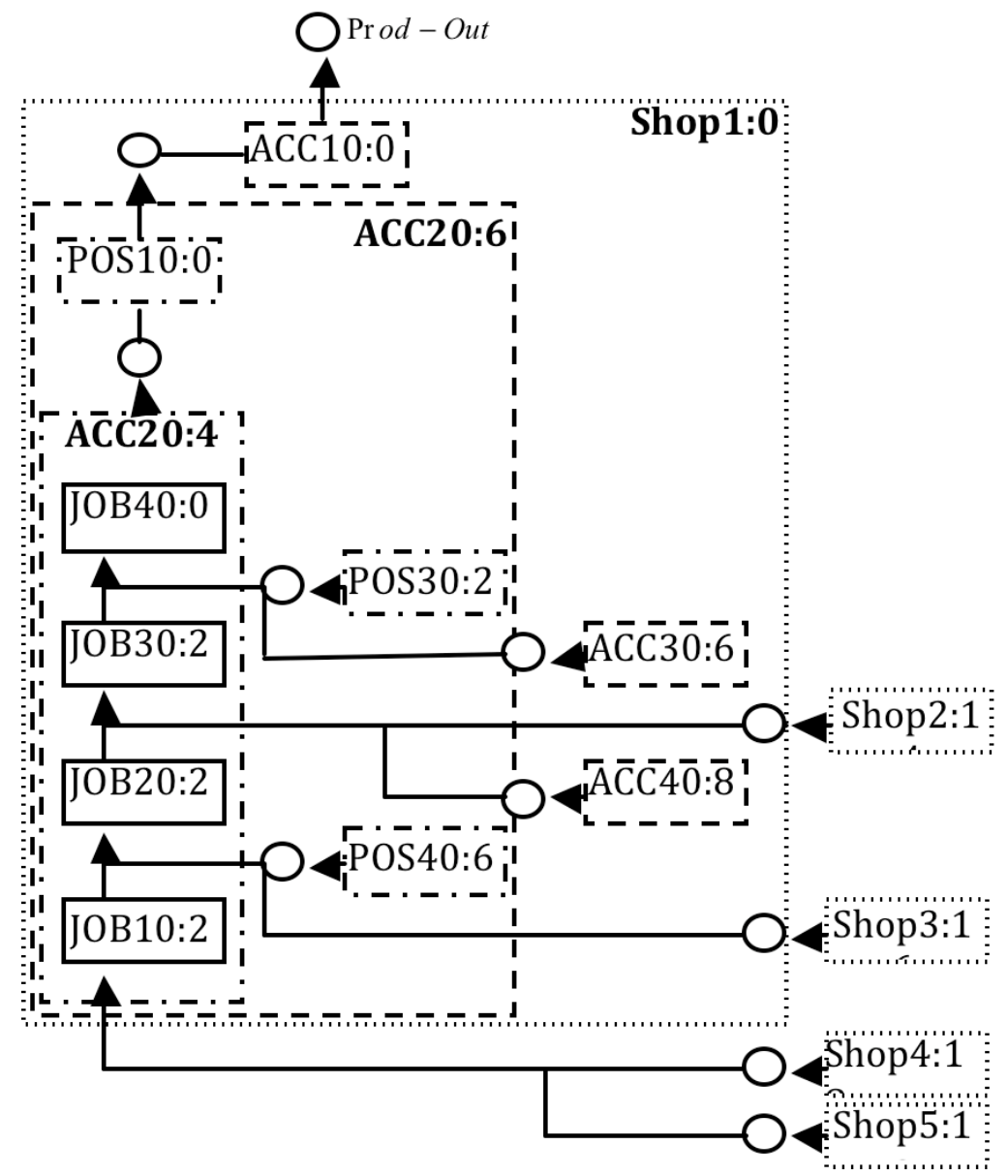

Fig. (7). Multi-level process flow example.

conveying time of each JOB. The ACC 20 output objects should be used 6 hours before the ACC 10 is completed, that means the lead time of the ACC 20 is 6 hours. The POS 20 output object should be completed 4 hours before the POS 10, that means the lead time of POS 20 is 4 hours. The delivery time of the product object $\operatorname{Pr}$ od -Out is 20 hours later. Try to compute the lead time of the flow units at different levels and make the flow unit production plan at different levels.

Based on the above computing method and equation of the lead time, the lead time of the flow units at different levels can be obtained. E.g. The output object of the POS 30 is used in the JOB 40, so its lead time should be lead time of the JOB 40, 0 hours plus the production cycle, 2 hours, which is equal to 2 hours. The ACC 30 is used at the JOB 40 of the POS 20, so its lead time should be the lead time of the POS 10,0 hours plus the lead time of the POS 20, 4 hours plus the lead time of the JOB 40, 0 hours and production cycle, 2 hours, which is equal to 6 hours. The value behind the flow unit names at different levels is the lead time of this flow unit in the Fig. (7).

Based on the lead time of the flow units at different levels and multi-level space production planning method and equation, respectively compute the production plan of the flow units at different levels in an inverse order of the process flow in turn from shop level to ACC level, POS level and JOB level. The results are shown as the Table $\mathbf{1 .}$
The computed results indicate that although the input objects of one flow unit are from the flow units at different levels and have different production lead time, their production completion and delivery time are the same. This result is consistent with actual case, which indicates that the computing method and production planning method of the lead time of multi-level process flow are correct and feasible.

\section{CONCLUSION}

This paper proposes multi-level process flow idea, which completely, clearly and truly reflects the actual manufacturing process of the product and complicated material flowing relation of space flow units at different levels, provides the theoretical basis for computing JOB, POS, ACC and shop lead time, and ensures correctness and reasonability of the production planning. Compared to the traditional method, the production lead time computed based on this idea is more precise and reasonable, can shorten the production planning period to much extent, includes rich and perfect information, and makes the made production plan comply with the actual manufacturing process more. So the multi-level process flow production planning method can provide complete and accurate planning information for production management process, facilitate connection of digital design and manufacturing in- 
Table 1. Computing results of delivery time.

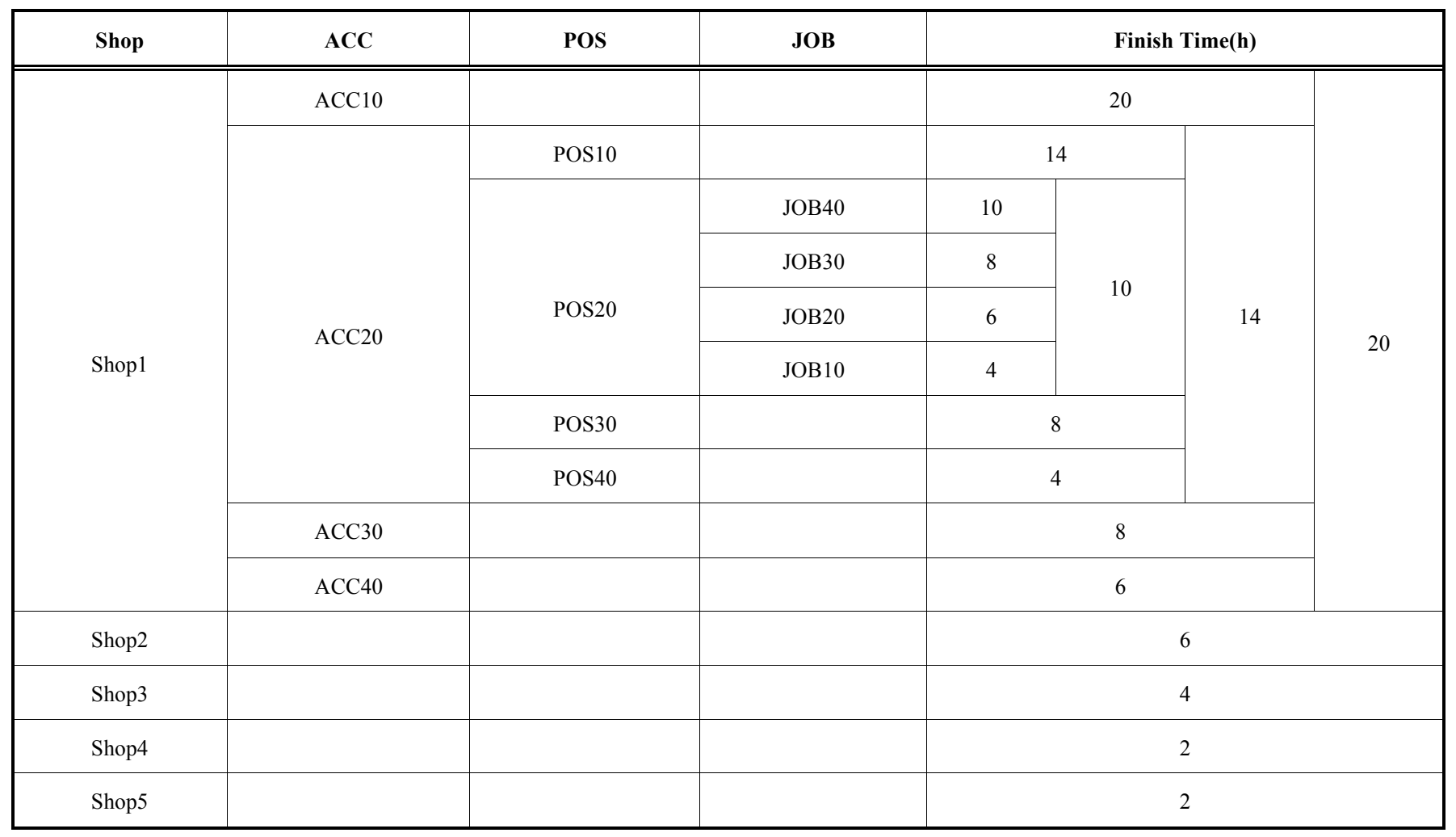

tegration flow, and further promote digital construction and deeper application and development of enterprises.

\section{CONFLICT OF INTEREST}

The authors confirm that this article content has no conflict of interest.

\section{ACKNOWLEDGEMENTS}

Project supported by the education department of Liaoning Province (L2012067).

\section{REFERENCES}

[1] Q. Zhou, and Y. Fan, "EBOP based research on complicated product process data model", Manufact. Automat., vol. 8, pp. 1518, August 2008.
[2] M. Liu, and F. Cao, "Process Planning Modeling to Support Product Life Cycle Data Management", J. Comput. Aided Design Comput. Graph, vol. 17, pp. 137-142, January 2005.

[3] X. Liu, and X. Huang, "Research on XBOM for Product Whole Life Cycle", Comput. Integrated Manufact. Syst., vol. 8, pp. 983987, December 2002.

[4] J. Wu, and W. Jiang, "Integration model and its evolution for product lifecycle", Comput. Integrated Manufact. Syst., vol. 15, pp. 1493-1513, August 2009.

[5] Z. Li, and X. Tian, "Single enterprise BOM-based process management system for aircraft manufacturing", J. Northwestern Polytech. Univ., vol. 26, pp. 771-776, June 2008.

[6] T. Xu, and J. Wang, "Bill of Material mapping technology based on process management", Comput. Integrated Manufact. Syst., vol. 17, pp. 1913-1920, September 2011.

[7] H. Xu, and X. Xu, "A Method of Generating Manufacturing BOM Based on Engineering BOM and BOP", China Mech. Eng., vol. 16, pp. 701-705, August 2005.

Received: September 16, 2014

(C) Qiu-zhong et al.; Licensee Bentham Open.

This is an open access article licensed under the terms of the Creative Commons Attribution Non-Commercial License (http://creativecommons.org/licenses/ by-nc/4.0/) which permits unrestricted, non-commercial use, distribution and reproduction in any medium, provided the work is properly cited. 